17. Stotland, N.L. "The myth of the abortion trauma syndrome". Jama, 1992; 268(15):2078-9.

18. Adler, N.E., David, H.P. et al "Psychological responses after abortion". Science. 1990;248(4951):41-4.

19. Kero, A., Högberg, U., Lalos, A. "Wellbeing and mental growth-long-term effects of legal abortion". Soc Sci Med. 2004;58(12):2559-69.

20. Pedroso, D., Gomes, E. Drezett, C. Adesse, J. L., Oliveira, M. J. A. In:Magnitude do aborto no Brasil - aspectos epidemiológicos e socioculturais. Rio de Janeiro: Ipas Brasil. p.175. 2006.

21. Drezett, J. In: Os novos desafios da responsabilidade política. Rio de Janeiro: Cepia. pp.53-70. 2005.

22. Centro de Referência da Saúde da Mulher. Violência sexual; protocolo de assistência e conduta para o atendimento de urgência. São Paulo: Secretaria de Estado da Saúde. 23p. 2008.

23. Pouchkarev, V.P., Shved, E.F., Novikov, P.I. "Sex determination of forensic samples by polymerase chain reaction of the amelogenin gene and analysis by capillary electrophoresis with polymer matrix". Electrophoresis. 1998; 19(1):76-9.

24. Oliveira, J.. Código Penal. São Paulo: Saraiva. 25a edição. p.486. 1987.

25. Brasil. Ministério da Saúde. "Anticoncepção de emergência: perguntas e respostas para profissionais de saúde". Brasília: Ministério da Saúde. 20p. 2005.

26. Faúndes, A, Brache, V, Alvarez, F. "Emergency contraception - clinical and ethical aspects". Int J Gynaecol Obstet. 2003;82(3):297-305.

27. Ugocsai, G, Rózsa, M, Ugocsai, P. "Scanning electron microscopic (SEM) changes of the endometrium in women taking high doses of levonorgestrel as emergency postcoital contraception". Contraception. 2002;66(6):433-7.

\section{ABORTO E SAÚDE MENTAL}

\author{
Daniela Pedroso
}

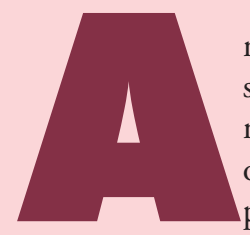

reprodução e o exercício da sexualidade deveriam ser sempre atos desejados e planejados, pois assim não ocorreriam gestações indesejadas, as quais ocorrem em um momento pouco favorável, inoportuno, ou contra a vontade (1).

Em uma época em que existem meios para regular a fertilidade, as mulheres ainda enfrentam esse problema devido aos seguintes fatores: as mulheres e seus parceiros desejam menos filhos; nem todos podem fazer controle de fertilidade; existem relaçōes sexuais que não são voluntárias e nem desejadas, cuja expressão extrema é a violência sexual, ou quando existe uma forte pressão social para o início da vida sexual, como acontece em alguns grupos de adolescentes; os métodos anticonceptivos falham, afinal eles não são $100 \%$ eficazes (1).

O momento da decisão em relação ao que fazer frente a uma gestação não desejada é um momento solitário e doloroso para a mulher e aqueles que a rodeiam, e traz inúmeras consequências. $\mathrm{O}$ abortamento não é visto pelas mulheres que o elegeram como uma preferível, ou desejável, forma de contracepção (2). O abortamento só ocorre porque uma gravidez é indesejada e somente as mulheres que tomam essa decisão sabem exatamente porque o fazem (3). A experiência de uma gestação não desejada, mais propriamente do que o abortamento por si só, pode ser a causa de alguma culpa ou depressão existente $(4,5)$.

Diante de uma gravidez indesejada, a mulher deve ser conscientizada da existência de opções frente à situação, a saber: manter a gestação até o seu término e inserir a futura criança na família, manter a gestação até o seu término e proceder com os mecanismos legais para o processo de adoção ou interromper a gestação através do abortamento (6). Os motivos que levam ao abortamento podem variar desde o risco de morte materna, anomalia fetal, gestação decorrente de violência sexual, até questôes pessoais (7).

A gravidez decorrente de violência sexual se destaca pela complexidade das reaçôes psicológicas, sociais e biológicas que determina (8). A gestação, indesejada ou forçada, é encarada por muitas mulheres como uma segunda violência (3). As respostas emocionais ao abortamento induzido legalmente são altamente positivas. Os problemas emocionais que resultam do abortamento são raros e menos frequentes do que aqueles que surgem após o parto de uma gravidez indesejada $(9,10)$. Estudos nos últimos 25 anos apontam o abortamento como um procedimento relativamente saudável em termos de efeitos emocionais. Há uma reação de alívio por parte das mulheres após o abortamento (4, $11,10,12,13)$, sendo que o mesmo não afeta desfavoravelmente a maioria das mulheres (14). Quase todas as mulheres assimilam a experiência do abortamento entre seis meses e um ano após o procedimento (14). 
Questionadas após o abortamento, acima de 98\% das mulheres não apresentaram remorso e fariam a mesma escolha novamente sob as mesmas circunstâncias (15). Mais de 70\% das mulheres expressaram desejo por uma criança no futuro $(16,17)$. Pode-se ainda afirmar que mulheres que abortaram não sofreram efeitos psicológicos adversos $(18,19)$.

A maioria das mulheres não experimentou problemas psicológicos ou arrependimentos dois anos após o abortamento (17). As adolescentes que escolheram abortar estão mais próximas de completar o ensino médio na idade esperada do que aquelas de status socioeconômico semelhante que levaram a gestação a termo (19).

Um estudo realizado oito semanas após o abortamento concluiu que: $70 \%$ das mulheres continuaram no seu relacionamento pré-abortamento, 5\% estabeleceram novos relacionamentos e 20\% não tinham parceiro sexual; $45 \%$ descreveram que seus sentimentos sobre seus parceiros não mudaram, 39\% se sentiram mais perto de seus parceiros e $16 \%$ se sentiram menos próximas de seus parceiros ou descreveram sentimentos variáveis; $46 \%$ sentiram que a qualidade de seus relacionamentos não mudou, $16 \%$ sentiram que seu relacionamento melhorou e $10 \%$ sentiram que seu relacionamento piorou; $98 \%$ das mulheres com companheiro retomou relacionamento sexual (20).

Quando uma mulher tem sua solicitação de abortamento negada, o risco para sua saúde mental é muito maior, na medida em que, sem escolha, enfrentará uma gravidez indesejada. Trinta e quatro por cento das mulheres que tiveram o abortamento negado reportaram que, de um a três anos, a criança se tornou um peso do qual frequentemente elas se ressentiam (15).

As respostas psicológicas ao abortamento são menos sérias do que aquelas experimentadas por mulheres que levam sua gestação indesejada a termo e decidem entregar a criança para adoção (12). Praticamente todas as mulheres acreditaram que doar o bebê poderia causar trauma emocional maior que o abortamento, considerando que poderiam desenvolver uma profunda afeição emocional com o bebê (14).

É possível afirmar que a "síndrome traumática do abortamento" é mais mito do que realidade (3), sendo que a Associação Americana de Psicologia não a reconhece e mais de 250 trabalhos científicos desmentiram a existência dessa síndrome (21).

A Associação Americana de Psicologia concluiu que o abortamento legal não cria danos para a maioria das mulheres submetidas ao procedimento. Vinte e um por cento das mulheres americanas realizam abortamento, portanto se houvesse severas reações emocionais existiria uma epidemia de mulheres procurando tratamento psicológico, o que não acontece (9).

Diante de tudo o que foi colocado, podemos levantar algumas questôes para reflexão futura: (i) Por que não podemos ser sensíveis ao direito de escolha dessas mulheres? (ii) Por que não deixar que as mulheres optem se desejam realizar ou não um abortamento? (iii) Por que não fazer valer o direito ao aborto enquanto direito humano das mulheres?

Daniela Pedroso é psicóloga do Núcleo de Atenção Integral à Mulher em Situação de Violência Sexual e Abortamento Legal do Hospital Pérola Byington, e mestranda em saúde materno infantil pela Universidade de Santo Amaro.

\section{REFERÊNCIAS BIBLIOGRÁFICAS}

1. Langer, A. \& Espinoza, H. "Embarazo no deseado: impacto sobre la salud y la sociedad en America Latina y el Caribe. Novos desafós de la responsabilidad política". Foro de la Sociedade Civil en las Américas. Cuadernos Del Foro; Vol.4, no.5, pp.95-101. 2002.

2. Henshaw, S.K.; Silverman, J. "The characteristics and prior contraceptive use of US abortion patients". Family Planning Perspectives, Vol.20, no.4, pp.158-9 \& 162-8. 1988.

3. Faúndes, A.; Barzelatto, J. O drama do aborto: em busca de um consenso. Campinas: Komedi. P.304.2004.

4. Adler, N.; Henry, D.; Major, B.; Roth, S.; Russo, N.; Wyatt, G. et al. "Psychological responses after abortion". Science;. Vol.248, no.4951, pp.41-4.1990.

5. Zolese, G.; Blacker, C. "Psychological complications of therapeutic abortion". British Journal of Psychiatric, Vol.160, pp.742-9.1992.

6. Brasil. Ministério da Saúde. Secretaria de Atenção à Saúde. Departamento de Ações Programáticas Estratégicas. Área Técnica de Saúde da Mulher. Prevenção e tratamento dos agravos resultantes da violência sexual contra mulheres e adolescentes. 2.ed. Atualizada e ampliada. Brasília: Ministério da Saúde; 68p. 2005(e).

7. Brasil. Ministério da Saúde. Secretaria de Atenção à Saúde. Departamento de Ações Programáticas Estratégicas. Área Técnica de Saúde da Mulher. Atenção humanizada ao abortamento. Brasília: Ministério da Saúde; 34p. 2005(d).

8. Faúndes, A.; Bedone, A.; Pinto e Silva J.L. I Fórum interprofissional para a implementação do atendimento ao aborto previsto na lei. $\mathrm{Fe}$ mina; Vol.25, pp.1-8.1999.

9. Adler, N. University of California at San Francisco, Statement on Behalf of the American Psychological Association Before the Human Resources and Intergovernmental Relations Subcommittee of the Committee on Governamental Operations, US House of Representatives; pp.130-40.1989.

10. Kero, A.; Hogberg, U.; Lalos, A. "Wellbeing and mental growth: long-term effects of legal abortion". Social Science \& Medicine; Vol.58, pp.2229-69. 2004.

11. Armsworth, M.W. "Psychological response to abortion". Journal of Counseling and Development; Vol.69, pp.377-9.1991.

12. Lazarus, A. "Psychiatric sequelae of legalized first trimester abortion". Journal of Psychosomatic Obstetrics \& Gynaecology; Vol.4, no.3, pp.140-50.1985.

13. D. H. Miller. In: Evaluating women's health messages: A resource book; Thousands Oaks, CA, pp.17-32. 1996.

14. P. Sachdev. Sex, abortion and unmarried women. Westport, СT: Greenwood Press. 1993.

15. Dagg, P.K.B. Am. J. of Psyc. Vol.148, no.5, pp.578-85. 1991.

16. Torres, A.; Forrest, J. D. Family Planning Perspectives; Vol.20, no.4, pp.196-76. 1988.

17. Major, B.; Cozzarelli, C; Cooper, M.L., Zubek, J.; Richards, C.; Wilhite, M.; Gramzow, R. H. Archives of General Psychiatry, Vol.57, no.777. 2000.

18. Russo, N.F.; Zierk, K.L. "Abortion, childbearing, and women's well-being". Professional Psychology: Research and Practice, Vol.23, no.4, pp.269-80.1992.

19. Zabin, L.S.; Hirsch, M.B.; Emerson, M.R.. Family Planning Perspectives. Vol.20, no.169.1989.

20. Ashton, J. R. Brit. J. Obst. and Gyn., Vol.87, no.1115. 1980.

21. Tyrer, L. B.; Grimes, D. Population and Development Review, Vol.15, no.172.1989. 